\title{
Peluang Baru dalam Jurnalisme Online
}

\author{
Aksan Sanjaya \\ STISIPOL PAHLAWAN 12, J1. Diponegoro No. 16, Sungailiat, Bangka 33215 \\ Telp/Fax. (0717) 92750
}

\begin{abstract}
ABSTRAK
Editor Media Sosial (EMS) adalah pekerjaan yang muncul dari penetrasi teknologi digital terhadap industri jurnalistik. Sebagai sebuah pekerjaan baru, Editor Media Sosial masih berada dalam posisi yang kurang jelas dalam ruang redaksi awalnya. Kendati adanya fakta yang membingungkan ini, namun masih saja ada orang dari ruang redaksi online yang ditugaskan untuk mencari perhatian komunitas lewat perbincangan maya, selain membuat posting terbaru mengenai suatu berita di beranda Facebook atau memberikan informasi tertentu pada laman Twitter. Karenanya, makalah ini ditujukan untuk mendefinisikan peranan EMS, posisinya dalam ruang redaksi dan organisasi media. Lebih lanjut, makalah ini juga mendiskusikan kecenderungan pekerjaan ini dan masa depannya

Disimpulkan bahwa masih ada banyak nama untuk mendefinisikan tugas sebagai EMS. Temuan lainnya juga menyimpulkan bahwa editor jenis ini telah terintegrasi ke dalam organisasi redaksi secara baik dan mampu beradaptasi dengan kerja ruang redaksi. Simpulan lainnya adalah bahwa EMS bekerja dalam ketrampilan ganda, yakni membuat para pengguna lain terlibat dalam proyek crowdsourcing sekaligus bagaimana mengirimkan berita yang bernilai tinggi kepada pembaca. Simpulan penting lainnya adalah EMS pada dasarnya adalah seorang jurnalis itu sendiri, sehingga ia harus membuat berita dalam secara cepat sekaligus bagaimana membuat berita tersebut akurat.
\end{abstract}

Kata kunci: Editor Media Sosial, Crowdsourcing 


\section{PENDAHULUAN}

Internet sebagai elemen penting dalam teknologi komunikasi menghasilkan perubahanperubahan penting dalam cara media massa memproduksi berita. Sebagai bagian dari teknologi komunikasi, internet telah membentuk jurnalime online sekaligus mengubah tipe pembaca dari pembaca cetak ke pembaca online.

Perubahan tersebut selanjutnya menuntut jenis pekerjaan baru berikut posisinya dalam organisasi media online masa kini. Salah satu bentuk perubahan memunculkan Editor Media Sosial (EMS) yang termasuk baru dikenal dalam industri jurnalisme online. Editor tipe ini bisa jadi semacam kebutuhan tak terelakkan ketika sebagian besar pembaca masa kini ada di ruang maya yang aktif di media sosial.

Pengguna internet di dunia yang mencapai sekitar tiga miliar telah mampu menggambarkan betapa besarnya potensi membaca masa kini. Bagi pemilik media, data di atas menuntut organisasi berita perlu berubah seiring keputusan media berpindah atau menambah dari medium cetak atau elektronik menjadi medium online.

Di lain pihak, pembaca kini adalah mereka yang aktif berselancar di media sosial, terutama di Indonesia sebagai salah satu pengguna media sosial terbesar di dunia. Oleh karenaitu, diperlukan Editor Media Sosial dengan kemampuan menghubungkan dua tren kenaikan di atas, antara pembaca potensial dengan ruang redaksi. Dengan demikian, akan tercipta ketersinambungan pesan, antara produsen informasi dengan pengguna.

Namun, sebagai sebuah pekerjaan baru, EMS masih berada pada posisi yang dilematis ketika dihadapkan dalam perspektif ruang redaksi. Dilema ini bisa jadi disebabkan belum adanya kejelasan deskripsi kerja dibanding dengan kerja editor web, redaktur, atau reporter.
Di satu sisi, perubahan-perubahan dalam teknologi komunikasi akan selalu berlangsung cepat dan massif sehingga membuat perubahan pada ruang redaksi pada masa-masa mendatang. Dalam prediksi ketidakpastian itu, tugas EMS bisa jadi berkembang, berubah atau hilang sama sekali.

Berdasarkan pengantar di atas, makalah ini ditujukan sebagai kajian untuk mengekplorasi definisi dan peranan Editor Media Sosial sebagai pekerjaan baru serta posisinya dalam organisasi berita masa kini. Kajian ini juga akan mendeskripsikan tren pekerjaan ini pada masa mendatang.

\section{KAJIAN TEORI}

Tim Currie (2012) dalam makalahnya "Social Media Editors in The Newsroom: A Survey of Roles and Functions, "melakukan kajian terhadap 13 editor media sosial di sejumlah kantor berita di Kanada untuk menentukan peranan dan fungsi dari pekerjaan dimaksud.

Terhadap sejumlah editor media sosial dimaksud, terbagi ke dalam dua kategori diantaranya; delapan orang berusia 20 hingga 30 tahun, dan punya pengalaman di bawah lima tahun di ruang redaksi. Hampir semuanya memiliki latar belakang jurnalistik. Umumnya telah bekerja sebagai reporter dua tau tiga tahun sebelum bergabung dengan unit digital di organisasi medianya. Sedangkan lima orang lainnya digambarkan sebagai editor senior. Ratarata berusia 35 tahun dan diasumsikan punya karir sebagai editor media sosial selama delapan tahun. Mereka juga mempunyai pendidikan jurnalistik.

Hasil kajiannya menemukan bahwa tugas sebagai editor media sosial sangat menantang terutama ketika berhadapan dengan fungsi sebagai penjaga gawang (the traditional gate-keeping), di 
lain pihak juga mewakilkan kepentingan pembaca di ruang redaksi.

Kajian lainnya menunjukkan bahwa editor media di Kanada yang telah terintegrasi dengan jalur kerja ruang redaksi, adalah yang telah bekerja secara dekat dengan reporter dan bertemu rutin dengan editor lain untuk menajamkan fungsi website.

Sementara itu ada sedikit bukti mengenai isolasi dari ruang redaksi sebagai bagian dari jurnalisme awal. Editor ini mempunya tempat di ruang redaksi dan aktif dan rapat redaksi. Meskipun tidak bisa disangkal, masih ada yang merasa di luar budaya ruang redaksi.

\section{Tanggung Jawab Baru Beragam}

Nama. Editor Media sosial (EMS) muncul sebagai jenis pekerjaan baru seiring kemunculan media sosial seperti Facebook (2004), Twitter (2006), LinkedIn (2003) dan Reddit (2010). Delapan tahun lalu, posisi sebagai Editor Media Sosial (EMS) pertama dikenal dalam organisasi berita besar semacam $B B C$, the New York Times, dan USA Today. Saat itu, umumnya tugas EMS bertanggung jawab membangun loyalitas dengan audiens online lewat perbincangan komunikasi dua arah antara editor dengan audiens.

AB Devito (2014) mengungkapkan bahwa tanggung jawab ini lebih relevan untuk audiens karena memperkuat kerja jurnalistik.

Mallary Jean Tenore (2010) mengatakan bahwa lebih banyak kantor berita seperti $N P R$, the Associated Press dan TBD mulai menyewa seseorang yang tugasnya berhubungan dengan karya jurnalistik dan media sosial.

Ada ragam nama untuk menyebut nama pekerjaan ini, sebagai contoh: Editor Media Sosial, Manajer Media Sosial, Manajer Komunitas dan Koordinator Media Sosial (Mediabistro,
2010). Stephanie Romanski dari Grand Island Independent disebut sebagai Koordinator Editor Web/Media Sosial. Dia mengatakan bahwa setelah bekerja selama beberapa tahun, akhirnya ia berani menyebut pekerjaannya sebagai "Koordinator Media Sosial” (Mediabistro, 2010).

Contoh yang lain, Robert Quigley disebut Editor Media Sosial untuk StatEMSan.com dan Austin360.com sejak 2009. Emily Stephenson dari Daily Tar Heel disebut Manajer Komunitas dan Angela Connor disebut Manajer Media Sosial di Capstrat Author (Mediabistro, 2010). Pada 2010, USA Today membuka lowongan pekerjaan sebagai Editor Media Sosial dan Analis Media Sosial untuk bertanggung jawab pada bagian media sosial (Summer Harlow. 2010). Tahun lalu, Al Jazeera juga mencari seseorang untuk ditempatkan pada posisi Manajer Editor Media Sosial.

Mencari nama yang tepat bisa jadi membingungkan sebab sejumlah media mainstream seperti contoh diatas punya visi yang beda mengenai pekerjaan itu sendiri.

Potensi pembaca. Adalah sebuah keniscayaan bahwa potensi pembaca online semakin besar. Pembaca jenis ini adalah pembaca baru sebagai bagian dari pengguna internet di dunia yang mencapai sekitar 3 miliar (wearesocia, 2015).

Khusus di Indonesia, data dari Asosiasi Penyelenggara Jasa Internet Indonesia (APII) menunjukkan pada kuartal I 2014, pengguna internet menembus 82 juta. Tentu saja, jumlah dimaksud akan terus meningkat seiring penetrasi teknologi internet yang semakin massif sepanjang 2014 hingga pertengahan 2016. Sebagai perbandingan, negara pengguna internet terbesar datang dari negara-negara berpenduduk besar: China, Amerika Serikat, India, Jepang dan Brazil, 
sebagai empat besar negara pengguna internet di dunia. Jadi, tren kenaikan untuk Indonesia adalah sesuatu yang alami.

Selain itu, hal yang tak kalah menariknya adalah semakin besarnya jumlah pengguna media sosial di dunia khususnya di Indonesia. Pengguna media sosial di dunia diperkirakan dua milyar pengguna (wearesocial, 2015). Selain itu para pengguna internet ini rata-rata mempunyai lima akun media sosial (Globalwebindex, 2014). Khusus untuk Indonesia, mencari informasi merupakan urutan dua alasan bagi pengguna ketika mengakses internet (APJII, 2014).

\section{METODE}

Kajian ini menggunakan metode kajian deskriptif. Jenis kajian ini ditujukan sebagai gambaran atas suatu gejala, peristiwa, atau kejadian yang terjadi saat sekarang. Kajian deskriptif memusatkan perhatiannya pada isu aktual masa kini yakni tentang suatu bidang pekerjaan yang muncul di era teknologi digital saat ini.

Kajian ini akan terfokus pada Editor Media Sosial sebagai pekerjaan yang muncul dalam era jurnalisme online. Kajian ini bersifat umum dengan berusaha menjelaskan kecenderungan umum pula tanpa dibatasi geografis (negara) atau kasus tertentu.

Sumber data diambil dari sejumlah literatur yang dimuat dari berbagai macam makalah, artikel atau jurnal ilmiah terutama dari internet yang berkaitan dengan topik dimaksud.

Jenis kajian ini termasuk dalam analisis kerja atau aktivitas, dimana termasuk dalam penelitian dengan metode deskriptif bertujuan mengeksplorasi rincian aktivitas dan pekerjaan manusia. Diharapkan dari hasil kajian, akan muncul rekomendasi-rekomendasi untuk keperluan selanjutnya.

\section{HASIL DAN PEMBAHASAN}

Tom Coates dari New Product Developing Englishman berpusat di San Francisco mengungkapkan bahwa penamaan bukanlah isu yang penting ketika membedakan jenis pekerjaan ini. Sebagai pekerjaan baru, ada banyak nama untuk jenis pekerjaan ini dalam industri jurnalisme yang berkembang dan berevolusi.

Tom menekankan pada visi ketika seseorang ditugaskan menjadi editor media sosial. Menurutnya, salah satu visi sebagai EMS bisa dimulai dari penguatan penetrasi media sosial lewat respon cepat terhadap apa yang orangorang kicau di Twitter (Meg Pickard, 2010).

Visi lainnya antara lain pengembangan koneksi media sosial dengan audiens yang berasal dari moderasi forum perbincangan, respon audiens, perancangan grup media sosial dan promosi isu-isu dalam media sosial (Meg Pickard, 2010).

Disini bisa diperhatikan bahwa meskipun ia punya beragam nama dan definsi, namun ada visi yang jelas dari tugas sebagai EMS. Editor media sosial tak melulu soal menulis link dan ringkasan cerita dari suatu berita di beranda Facebook lalu selepas itu selesai. Visinya terhadap pekerjaan dituntut untuk melebar dan berkembang.

Seperti disampaikan oleh Meg Pickard (2010), kepala urusan digital, dari Guardian News \& Media yang mengamini pendapat Tom Coates bahwa dalam organisasi berita, editor media sosial seharusnya lebih aktif dalam pelibatan komunitas dibandingkan memperbaharui status atau tweeting.

Secara rinci Meg menyampaikan bahwa visi dari seorang Editor Media Sosial adalah 
bertanggung jawab dalam proyek penulisan berita secara gotong royong (crowdsourcing) dan proyek lain yang melibatkan kerja komunitas termasuk mempengaruhi dan mengadvokasi interaksi media sosial dengan teman-teman editor (Meg Pickard, 2010).

Bagaimanapun EMS tidak sama dengan kerja redaktur di media online. Redaktur di media online bisa jadi disebut Editor Web. Meskipun kelihatan membingungkan, Editor web tugasnya secara jelas bertanggung jawab dalam proses menggali informasi (chungking), distilling, membuat judul yang pas, anak judul dan ringkasan berita sebelum dipublikasikan (Foust, 2005).

Sedangkan EMS tugas semakin berkembang tergantung pada kebutuhan tiap media arus utama tempat dia bekerja. Tim Currie menjelaskan EMS merupakan jurnalis yang berfokus pada penciptaan perbincangan dengan audiens (Tim Currie, 2012). Disaat bersamaan, DeVito menyatakan EMS didefinisikan sebagai seseorang yang membantu menyebarkan informasi bernilai berita dan terlibat dengan audiens (A.B. Devito, 2014).

Meskipun ada batas tipis diantara banyak konsep seperti: editor, manajer, direktur atau manajer komunitas namun penting untuk mengenali karakteristik pada tiap pekerjaan tertentu yang menuntut keahlian tertentu pula. Pada ruang redaksi media online, ada kebijakan operasional dan redaksional. Meg mengungkapkan bahwa mengenali perbedaan antara kebijakan redaksional dan operasional dengan pendekatan editorial yang berfokus pada komunitas dan isi adalah hal yang sangat penting (Mallary Jean Tenore, 2010).

\section{Posisi dalam Organisasi Berita.}

Sebagai sebuah pekerjaan baru, EMS kerap ditempatkan dalam beragam posisi dan jenis hubungan dalam struktur redaksi, sehingga membuatpekerjanyamenjadisedikitkebingungan. Hal yang alamiah karena jenis pekerjaan ini selalu dinamis dan menuntut ketrampilan tersendiri. Ketrampilan terutama pada berfikir dan menulis kreatif yang kadang berasal dari intuisi dan pengalaman. Tim Currie (2012) mencontohkan EMS di Kanada kebanyakan merasa di luar jaringan budaya redaksi. Meskipun mereka harus berkelahi dengan redaktur lain karena EMS bekerja berdasarkan evaluasi intuisi dibanding data. Terkadang staf lain berfikir skeptis pada pekerjaan sebagai EMS terutama relevansinya dengan media sosial. Disinilah EMS dituntut untuk berjuang menjelaskan lebih banyak nilai media sosial daripada proses pelaporan berita.

Dalam kajiannya, rasa asing ini tidaklah mutlak. A.B. Devito (2014) dalam penelitiannya mengungkapkan sebaliknya rasa asing dimaksud dapat mengikis fungsi ruang redaksi sebagai satu-satunya penjaga gawang (information gatekeeper). Devito lebih lanjut mengungkapkan bahwa posisi EMS dapat terintegrasi ke dalam organisasi editorial dan hampir terhubung dengan beragam posisi lainnya. Baginya, tidak ada bukti nyata rasa keterasingan karena EMS sekarang mulai aktif dalam rapat redaksi, dan hampir sebagian besar dari mereka berlatar pendidikan jurnalistik.

Fakta bahwa banyak setiap orang dapat menjadi the gatekeeper dengan beragam tugasnya tersebut bisa jadi alasan mengapa The New York Times di 2010 memposisikan EMS dari satu orang menjadi kerja tim. Meskipun, reposisi tugas ini menghilangkan tugas Jennifer Preston sebagai EMS pertama di NYT dan menempatkannya 
sebagai reporter media sosial (Mallary Jean Tenore, 2010).

Pada perkembangan selanjutnya, EMS di NYT selanjutnya berubah dan dikembangkan masuk kedalam Interactive News Division dibawah kepemimpinan Editor Berita Interaktif yang dijabat oleh Aron Pilhofer (Mallary Jean Tenore, 2010).

Megan Garber (2010) mengomentari perubahan itu sebagai tanda kemenangan media sosial atas kertas. Megan mengatakan bahwa organisasi berita adalah tempat dimana sejumlah pengaruh yang unik antara tradisi dan teknologi dikembangkan. Media sosial, pada suatu masa telah mengalami evolusi, sesuatu yang jauh lama berlangsung sebelum Preston menjabat EMS.

Di satu sisi, EMS dulunya adalah sebuah pekerjaan sendiri - kemudian berkembang menjadi pekerjaan tim. Hal ini menunjukkan bahwa pekerjaan ini bersifat dinamis dan progresif yang mempengaruhi visi ruang redaksi terhadap penggunaan media sosial.

Sebagai sebuah pekerjaan tim, divisi EMS dapat terdiri dari beberapa orang dengan tugas yang jelas. Sebagai contoh, Redaksi berita interaktif dari The New York Time terdiri atas sepuluh pengembang dan satu staf tambahan yang bekerjasama dengan jurnalis, produser web, bagian bisnis, dan karyawan lain dari bagian redaksi (Megan Garber, 2010).

Meghan Peters (2013) yang bekerja sebagai Direktur Komunitas di Mashable membawahi tim dengan empat anggota. Sementara itu, The Wall Street Journal yang punya tim dengan tujuh orang menangani isu-isu dalam media sosial, baru-baru ini menunjuk Liz Heronas sebagai Direktur Media Sosial.

Model organisasi di atas seperti digambarkan oleh Megan sebagai peningkatan yang penting dari kerja EMS yang solo menjadi kerja tim (Megan Garber, 2010). Pendapat yang senada disampaikan oleh Preston, baginya media sosial tidak milik satu orang; ia perlu menjadi bagian kerja semua orang. Menurutnya, jenis pekerjaan EMS perlu terintegrasi ke dalam proses pemberitaan di ruang redaksi (Mallary Jean Tenore, 2010).

\section{Deskripsi Kerja EMS.}

Pada umumnya, tugas EMS dapat diidentifikasi sebagai jembatan antara ruang redaksi dengan pembaca potensial yang tersebar di sejumlah media sosial. Selain posting berita di Facebook atau tweet link berita di beranda rEMSi akun media, A.B Devito (2014) menyatakan EMS pada dasarnya melakukan sejumlah kegiatan semacam melatih rekan, terlibat dengan audiens, mengembangkan karya jurnalistik, meraih tujuan media dan menghadiri rapat redaksi. Peran lainnya seperti dikemukakan oleh Tim Currie (2012) dalam surveinya menemukan bahwa tugas EMS antara lain melatih dan mendukung sesama rekan jurnalis, terlibat dengan audiens, merancang tujuan jangka panjang, menghadiri rapat redaksi, dan melakukan perbincangan maya (online chat). Menurut Tim, diantara tugas itu, posting materi berita di media sosial dan melatih sesama rekan jurnalis adalah tugas yang kerap dilakukan oleh EMS.

Selain hal-hal diatas, peran EMS juga berkembang sebagai penarik minat pembaca untuk memproduksi berita juga. Media menyediakan kanal khusus untuk menarik minat para pembaca untuk sekaligus menjadi produsen informasi ini atau biasa dikenal dengan crowdsourcing. Hal yang dapat ditemui pada the Huffington Post atau Kompasiana.

Seperti diungkapkan oleh Ricardo Bilton 
(2014) bahwa salah satu peran dari EMS adalah menemukan medium distribusi berita dan sharing berita lewat medium crowdsourcing. Hal senada diungkapkan oleh Daniel Victor, editor staf Media sosial dari the New York Times bahwa selain posting dan tweeting, mereka juga bekerja di ruang redaksi untuk proyek crowdscourcing yang memakan waktu yang lama (Ricardo Bilton, 2014).

Ketika EMS memainkan perannya dalam melibatkan pengguna, pada dasarnya ia telah menjalankan tugas profesionalnya. Melanie Stone (2014) mengungkapkan bahwa penerapan pelibatan pengguna adalah hal yang penting sebagai bagian tugas dari EMS, sehingga ia dituntut untuk fokus pada kreatifitas dan pemahaman atas yang orang fikir terhadap isu tertentu.

Ketrampilan ini pada akhirnya menuntut mereka lihai dalam proses seleksi informasi dan meneruskannya. Seperti diungkapkan oleh Anthony De Rosa (2011), EMS dari Reuters bahwa EMS seharusnya menjadi kurator dan navigator karena dia dapat memproduksi berita dari warga dan juga ruang redaksi. Ketrampilan akan dua hal tersebut pada akhirnya membuat kerja EMS semakin unik.

Unik pun tak cukup, sebab EMS harus bekerja di ruang kreatif. Rubina Fillion, seorang EMS dari the Wall Street Journal mengakui bahwa dia dan timnya selalu bersiap untuk peristiwa di depan yang akhirnya menuntut mereka untuk lebih kreatif, berfikir masa depan, merancang ide-ide untuk menarik perhatian audiens (Melanie Stone, 2014).

\section{Tren Masa Depan}

Tim Currie (2012) menyimpulkan bahwa potensi EMS akan berkembang seiring dengan pengaruh pembaca/audiens yang mereka wakilkan. Pembaca yang besar ini akan menentukan fungsi penjaga gawang yang di lakukan oleh redaktur dalam meliput dan membagi berita.

Hal ini bisa dikatakan bahwa pekerjaan EMS akan terus tumbuh dan berkembang. Seperti diungkapkan oleh Rob Fishman dari Buzzfeed bahwa EMS tidak akan mati (Mallary Jean Tenore. 2013). Pandangan optimis disampaikan oleh Megan Peters (2013) bahwa EMS akan makin mapan untuk tahun-tahun mendatang.

Melihat tugas dan fungsinya, tren pekerjaan ini tentu saja tak akan mati, sebab EMS adalah tugas yang berhubungan dengan teknologi komunikasi yang pada kenyataanya berkembang massif. Mark Briggs, direktur media digital di KING5 Seattle menjelaskan bahwa selalu diperlukan pusat sebaran untuk mengembangkan teknologi dan membuat suatu organisasi tambah bersemangat. Mark menyimpulkan pekerjaan ini akan berkembang dan mapan untuk tahun mendatang. Mark menjelaskan bahwa diperlukan seseorang yang bisa berada di depan semua orang untuk suatu pengalaman baru (Megan Peters, 2013).

Pendapat senada disampaikan oleh Mallary Jean Tenore (2013), bahwa pekerjaan ini akan berkembang karena akan ada banyak orang yang menggunakan jaringan media sosial untuk berbagi dan membaca suatu informasi.

Untuk tahun mendatang, tantangan EMS bisa jadi bagaimana memperbaiki dan menolak suatu informasi (Steve Myers, 2011). Tantangan lainnya bisa jadi mengenai kecepatan dan bagaimana membuat informasi tetap akurat. Veronica de Souza, EMS di Digg, mencontohkan kesalahan editor dalam situasi berita langsung, pada saat pemboman di acara maraton di Boston di Twitter. 
Karenanya, dalam hubungan dengan berita langsung, Veronica menyarankan kunci penting selain kecepatan yakni bagaimana mendapatkan informasi yang akurat dari sejumlah orang (Ricardo Bilton, 2014).

Tantangan lainnya adalah bagaimana praktik pelibatan pengguna dimasukkan dalam peran EMS. Melani Stone (2014) mengatakan bahwa EMS perlu untuk fokus pada kreatifitas dan kemampuan memahami apa yang orang fikir mengenai isu tertentu pada waktu tertentu.

Bagaimanapun, tugas mendasar dan paling menantang adalah memenuhi ketrampilan yang diperlukan oleh tradisi kuat jurnalisme. Editor The New York Times, Roston mengatakan bahwa suratkabar akan perlu orang-orang yang berpengalaman menulis dan mengedit. Ia menyimpulan bahwa bagus untuk cerdas dalam bermedia sosial seperti Twitter, Facebook, Instagram atau Reddit, namun jika dia tidak memiliki standar kerja jurnalistik yang tinggi, akan sulit mendefinisikan seseorang sebagai Editor Media Sosial sesungguhnya (Melani Stone, 2014).

\section{KESIMPULAN}

Editor Media Sosial punya beragam definisi dan penamaan. Namun, media mainstream kini sepakat bahwa visi pekerjaan ini tak semata-mata soal posting atau tweet informasi baru di beranda media sosial. Tanggung jawab EMS berkembang dan meluas terutama bagaimana merangsang pengguna media sosial untuk terlibat dalam perbincangan terhadap suatu berita.

Visi yang lainnya adalah bagaimana komunitas ini dapat dilibatkan dalam proyek bersama, misalnya crowdsourcing. Suatu kegiatan antara pengguna media sosial untuk juga memproduksi berita lalu mengirimkannya dalam medium online bersama. Pada praktiknya hal ini bisa dilihat pada, kompasiana milik kompas, atau netcj.tv, dengan tagline, "everybody can be a journalist" itu.

Simpulan berikutnya adalah mengenai posisi Editor Media Sosial yang dalam kenyataannya berkembang secara progresif sesuai kebutuhan masing-masing media. Namun satu hal yang pasti, EMS telah terintegrasi ke dalam ruang redaksi yang berkaitan dengan bidang-bidang lainnya. Ketika ia masuk ke dalam struktur ruang redaksi, ia melebur dan bekerja secara integral dengan redaktur, reporter, atau penyiar lainnya. Dalam kenyataan ini, EMS telah membuktikan dirinya menjadi seorang gatekeeper sama halnya wartawan atau jurnalis lainnya.

Selanjutnya, ketika ia melebur dengan ruang redaksi, tugas EMS tak lagi dipikul satu orang. Kini, sejumlah media mainstream mempekerjakan tim media sosial yang bisa jadi terdiri dari manajer atau direktur membawahi sejumlah pengembang (developer) dan staf pendukung. Kerja tim ini pada akhirnya mengukuhkan kepentingan dan urgensi dari EMS.

Poin berikutnya adalah tugas EMS yang lebih dari posting berita di media sosial atau sekedar mentweet link berita baru yang diupdate dari website rEMSi berita. Tugasnya telah membentang diantaranya bagaimana melibatkan pengguna untuk terlibat dalam perbincangan maya. Hasil akhirnya adalah proyek produksi berita secara bersama antara sesama pengguna (crowdsourcing).

Pelibatan pengguna semacam ini menuntut EMS untuk punya ketrampilan ganda, sebagai kurator dan navigator. EMS dituntut dapat memancing pelibatan warga untuk mengirimkan berita ke kanal sekaligus mengirimkan berita dari ruang redaksi utama. Ketrampilan ganda ini 
menjadikan EMS bertugas dalam wilayah antara pengguna dan ruang redaksi. Selain hal tersebut. EMS juga dituntut untuk mampu berfikir kritis dan kreatif terhadap isu-isu yang akan muncul.

Pada akhirnya, pekerjaan EMS akan terus berkembang seiring perkembangan teknologi komunikasi. Akan dibutuhkan mereka yang punya ketrampilan dan kemampuan intuisi untuk melibatkan pengguna sehingga informasi dapat tersampaikan secara baik.

Tantangan sesungguhnya adalah bagaimana Editor Media Sosial dapat bekerja secara cepat dan akurat. Kecepatan sangat diperlukan dalam industri media online yang berubah cepat di tengah kompetisi yang ketat. Namun, kecepatan bukanlah segalanya, diperlukan kebenaran atas setiap informasi yang disajikan. Membuatnya tetap akurat sesuai fakta berdasarkan kaidah jurnalistik adalah suatu hal yang mendasar dan penting. Karena sesungguhnya Editor Media Sosial adalah jurnalis yang tetap bekerja dalam kaidah dan standar jurnalistik.

\section{SARAN}

Dalam era media sosial yang berkembang dan progresif diperlukan pemahaman mendalam mengenai tugas dan fungsi editor media sosial sebagai wakil media untuk menarik calon pembaca.

Media-media online di Indonesia seyogyanya menugaskan seorang EMS yang berasal dari latar belakang jurnalistik dan mampu mengembangkan kemampuan media sosialnya. Kemampuan ganda ini akan berimplikasi positif bagi efektifitas berita yang disampaikan secara online.

Editor media sosial adalah pekerjaan yang potensial untuk tahun-tahun mendatang. Tugas selanjutnya bukan hanya untuk media berita online, namun pula EMS dapat diberdayakan pada instansi pemerintah sebagai bentuk tanggung jawab publik.

\section{DAFTAR PUSTAKA}

Foust, J. C. (2005). Online journalism. Scottsdale, Arizona: Holcomb Hathaway.

DeVito, Allyson Beutke. (2014)."The Role of Social Media Editors in Television Newsrooms: An Exploratory Study."

\section{Sumber Internet}

Asosiasi Penyedia Jasa Internet Indonesia. "Profil Pengguna Internet Indonesia 2014." apjii.or.id. Maret 2015. Diakses pada 10 Agustus 2016 dari https://apjii.or.id/ content/read/39/27/PROFIL-PENGGUNAINTERNET-INDONESIA-2014

"alJazeera Jobs - Social Media Editor Manager."alJazeera. 9 November 2014. Diakses pada 10 Agustus 2016,dari http:// www.aljazeerajobs.com/jobs/va cancies/ Saudi_Arabia/Social-Media-EditorManager-852358.html.

Denis Ugur. "Internet Users Have Five Social Accounts." Wearesocial. com. 28 Oktober 2014. diakses pada 10 Agustus 2016 dari http://wearesocial.com/ $\underline{\mathrm{uk} / \mathrm{b} \log / 2014 / 1 \quad 0 / \text { internet-users-5-social- }}$ accounts

Justin Ellis. "Anthony De Rosa on becoming Reuters social media editor and the ambient wire for news." NiemanLab. 8 July 2011. Diakses pada 10 Agustus 2016 dari http:// www.niemanlab.org/2011/07/the -big-soupanthony-de-rosa-on-becoming-reuterssocial-media-editor-and-the-ambient-wirefor-news/.

Mallary Jean Tenore. "Why The New York Times eliminated its social media editor." Poynter. org. 10 Desember 2010. Diakses pada 7 Agustus 2015 dari http://www.poynter.org/ mediawire/top-stories/110111/why-the-newyork-times-eliminated-its-social-mediaeditor-position/.

Meg Pickard.'What are the responsibilities of a Social Media Editor?." Quora. 20 November 2010. Diakses pada 7 Agustus 2016 dari http://www.quora.com/What-are-theresponsibilities-of-a-Social-Media-Editor>

Megan Garber. "Aron Pilhofer and 
Jennifer Preston on the new shape of Social."NiemanLab. 9 December 2010. Diakses pada 8 Agustus 2016 dari http:// www.niemanlab.org/2010/12/aro n-pilhoferand-jennifer-preston-on-the-new-shape-ofsocial-in-the-new-york-times-newsroom/.

Meghan Peters. "The Job of Social Media Editor Isn't Dead, It's Maturing."Mashable.11 Juni 2013. Diakses pada 9 Agustus 2016 dari http://mashable.com/2013/06/11/socia 1-media-editors-rise-again/.

Melanie Stone. "Social Media Editors in the Newsroom: What the Job is Really like."pbs.org. 17 Maret 2016. Diakses pada 10 Agustus 2016 dari http://www.pbs.org/ mediashift/2014/0 3/social-media-editorsin-the-newsroom-what-the-job-is-reallylike/.

Ricardo Bilton. Beyond tweeting: Demystifying the social media editor."digiday.com. 27 February 2014. Diakses pada 10 Agustus 2016 dari http://digiday.com/publishers/ whats-social-media-editor-good-anyway/.

Simon Kemp. "Digital, Social, and Mobile Worldwide in 2015." wearesocial.com. 21 Januari 2015. Diakses pada 10 Agustus 2015 dari http://wearesocial.com/uk/ special-reports/digital-social-mobileworldwide-2015

Summer Harlow. "Changes in social media editors at USA Today, New York Times." The Knight Center for Journalism at the University of Texas at Austin.10 Desember 2010. Diakses pada 10 Agustus 2016 dari https://knightcenter.utexas.edu/blog/c hanges-social-media-editors-usa-todaynew-york-times.

Tim Currie. "Social Media Editors in the Newsroom: a Survey of Roles and Functions." AEJMC 2012 Chicago Conference.9 Augustus 2012. Diakses pada 10 Agustus 2016 dari http:// timcurrie.ca/docs/currie_aejmc2 012 . pdf.

"What exactly is a social media editor/manager?." Mediabistro. 6 April 2010. Diakses pada 10 Agustus 2016 dari http://www.mediabistro. com/10000wo rds/what-exactly-is-socialmedia b413. 